\title{
Alexander Milchev-a tribute on the occasion of his 70th birthday
}

\author{
Vessela Tsakova
}

Published online: 18 November 2012

(C) Springer-Verlag Berlin Heidelberg 2012

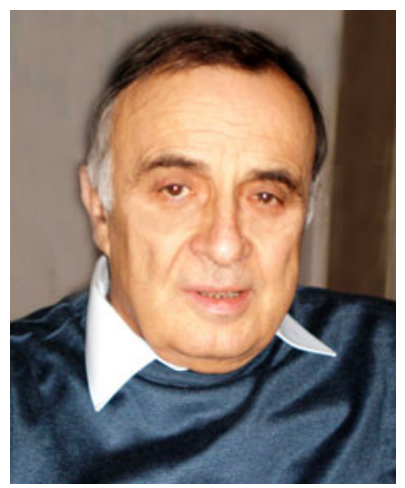

With this Special issue, the Journal of Solid State Electrochemistry celebrates the 70th birthday of Alexander Milchev, Professor at the Rostislaw Kaischew Institute of Physical Chemistry, Bulgarian Academy of Sciences, a well-known scientist in the field of electrocrystallization.

Alexander Milchev was born on January 7, 1943 in Giumurdzhina (now Komotini, Greece). He received his MSc degree in chemistry from the Sofia University in 1968. The early contacts with Professor Rostislaw Kaischew who at that time was university professor and head of the Institute of Physical Chemistry at the Bulgarian Academy of Sciences predetermined both his academic career and his long-term scientific interests. Alexander Milchev started working at the Institute of Physical Chemistry as a student and in the same institution advanced from $\mathrm{PhD}$ student to full professor. He was involved in experimental and theoretical studies of the initial stages of electrochemical phase formation and published papers on this topic during his entire scientific life. Already in 1974, he authored, together

\footnotetext{
V. Tsakova $(\bowtie)$

Rostislaw Kaischew Institute of Physical Chemistry, Bulgarian Academy of Sciences, Sofia, Bulgaria

e-mail: tsakova@ipc.bas.bg
}

with R. Kaischew and S. Stoyanov, two papers on the atomistic theory of electrochemical nucleation that opened the way for a new treatment of the nucleation kinetics.

In the early stage of his career, Alexander Milchev got the chance to work for a while with Professor Graham Hills at the University of Southampton, UK, exactly at the same time (1978) when Benjamin Scharifker, another respected name in the electrochemical nucleation and crystal growth field, was completing his $\mathrm{PhD}$ thesis at that University. The contacts with "Ben" remained vivid throughout the years.

In the long run of his scientific career, Alexander Milchev was involved in numerous most fruitful collaborations with scientists all over Europe. He worked as an Alexander von Humboldt fellow with Wolfgang Lorenz (University of Karlsruhe, Germany) and Rolf Lacmann (Technical University of Braunschweig, Germany). As a guest scientist, he visited Margarete Sluyters-Rehbach and Jan Sluyters (University of Utrecht, The Netherlands), Claudine Buess-Hermann (Free University of Brussels, Belgium), Luc Heerman (University of Leuven, Belgium), and Georgios Kokkinidis (University of Thessaloniki, Greece). He still maintains close contacts with scientists involved in studies of electrochemical nucleation and growth phenomena all over the world.

In the same time, Alexander's laboratory in Sofia was open to many foreign guests coming from Russia, Belgium, Argentina, and Greece. To work in Alexander's laboratory at the Institute of Physical Chemistry in Sofia was always a challenge - high quality and most reliable experimental work together with extensive theoretical background were strongly required. The scientific discussions with him went quickly to the very heart of the problem and were not finished before all arguments became exhausted and all possible viewpoints have been addressed. To argue with him on scientific problems was both challenging and deeply 
rewarding. Many young Bulgarian and foreign scientists have worked over the years in his lab. They all were trained according to the high standards of his own work.

Alexander Milchev has published about 100 papers that address mainly the initial stages of electrochemical phase formation in various experimental systems. As a former co-worker and a $\mathrm{PhD}$ student of him, I have witnessed the careful planning of all experiments in a way that allowed approaching specific aspects of the investigated systems, checking also the validity of various theoretical concepts. The coupling of theory and experiment was the intrinsic characteristic of his work that resulted in important achievements in the understanding of electrochemical phase formation phenomena. He published several review papers on electrochemical nucleation and growth and the seminal monograph "Electrocrystallization: Fundamentals of nucleation and growth" that gathers the knowledge accumulated all over the years of his successful scientific career.

Alexander is not only writing scientific papers but is also inventing jocular rhymes intended to entertain his colleagues and friends. He is a passionate reader of good books and talented teller of exquisite stories.

At present, Alexander Milchev is a member of the Commission for natural sciences at the Ministry of Education and Science of Republic Bulgaria. Since 2006, he is also a national representative in the Commission on Physicochemical Symbols, Terminology and Units of IUPAC.

As a guest editor of this Special issue, I would like to express my sincere gratitude for the warm response of the numerous collaborators and friends of Alexander that contributed to this issue. I was glad to receive response also from scientists that did not know him personally but were well aware of his work and joined the issue. I really hope that Alexander will enjoy reading the papers that are collected here and present to a great extent investigations closely related to his area of research. Let us all wish him good health and much success in his further scientific pursuits.

On behalf of the students and friends of Alexander Milchev, and on behalf of the editors of the Journal of Solid State Electrochemistry,

Vessela Tsakova 